\title{
Multiple intestinal hemangioma concurrent with low-grade appendiceal mucinous neoplasm presenting as intussusception-a case report and literature review
}

Yanhua Yang, Dongmei Jia and Chen Jiang ${ }^{*}$

\begin{abstract}
Background: Cases with intussusception caused by either intestinal hemangiomas or appendiceal mucinous neoplasms are extremely rare.

Case presentation: In this study, we reported a 47-year-old male presented with paroxysmal abdominal pain and postprandial bloating for 3 days. CT results indicated a high possibility of secondary intussusception in ascending colon. Histopathology indicated a mixed type of cavernous and capillary hemangioma, combined with low-grade appendiceal mucinous neoplasms (LAMNs) and intestinal obstruction. The patient underwent laparotomy and right hemicolectomy. Finally, the patient was followed up for 4 months with no disease progression.

Conclusions: Rare studies reported the intestine hemangiomas coincided with appendix low-grade mucinous tumor. Its manifestations are not specific, which is a challenge in the preoperative diagnosis. For cases with intussusception that was not observed in time, it may lead to intestinal necrosis and diffuse peritonitis. Additionally, the ruptured mucinous tumor in the appendix may lead to pathogenesis of pseudomyxoma peritonei. Therefore, accurate diagnosis and appropriate surgery-based treatment contribute to the improvement of prognosis and severe outcomes among these patients.
\end{abstract}

Keywords: Multiple intestinal hemangioma, Low-grade appendiceal mucinous neoplasm, Intussusceptions, Laparotomy, Hemicolectomy

\section{Background}

Gastrointestinal (GI) hemangiomas are uncommon benign vascular tumors that may occur in any part of the GI tract. According to the size of the involved vessels, hemangiomas are histologically classified into cavernous, capillary, or mixed-type tumors. Cavernous type is the most common, while multiple hemangiomas are very rare. Mucinous neoplasm of the appendix is featured by mucinous epithelial proliferation combined

*Correspondence: 1744392098@qq.com

Department of Pathology, Qingdao Municipal Hospital, Qingdao 266071 , China with extracellular mucin and pushing tumor margins. According to the 2019 WHO classification of tumors of the digestive system [1-3], appendiceal mucinous neoplasm was defined as hyperplastic polyp, serrated lesions, low-grade appendiceal mucinous neoplasms (LAMNs), high-grade appendiceal mucinous neoplasms (HAMNs), as well as mucinous adenocarcinoma of appendix, which present with or without appendiceal perforation. To our best knowledge, appendiceal mucinous neoplasms and intestinal hemangiomas are rare in clinical practice. Besides, cases with intussusception caused by either intestinal hemangiomas or appendiceal mucinous neoplasms are extremely rare. In this study, we reported a original author(s) and the source, provide a link to the Creative Commons licence, and indicate if changes were made. The images or other third party material in this article are included in the article's Creative Commons licence, unless indicated otherwise in a credit line to the material. If material is not included in the article's Creative Commons licence and your intended use is not permitted by statutory regulation or exceeds the permitted use, you will need to obtain permission directly from the copyright holder. To view a copy of this licence, visit http://creativecommons.org/licenses/by/4.0/. The Creative Commons Public Domain Dedication waiver (http://creativeco mmons.org/publicdomain/zero/1.0/) applies to the data made available in this article, unless otherwise stated in a credit line to the data. 
rare case with simultaneous occurrence of LAMNs and diffuse intestinal hemangioma.

\section{Case presentation}

A 47-year-old male patient was admitted to the Emergency Department in our hospital due to paroxysmal abdominal pain and postprandial bloating for 3 days.

Table 1 Results of the laboratory examination

\begin{tabular}{lll}
\hline Items & Results & Normal range \\
\hline White cell count & $7.62 \times 10^{9} / \mathrm{L}$ & $3.5-9.5 \times 10^{9} / \mathrm{L}$ \\
Neutrophils & $73.1 \%$ & $40-75 \%$ \\
RBCs & $5.16 \times 10^{9} / \mathrm{L}$ & $4.3-5.8 \times 10^{9} / \mathrm{L}$ \\
Hemoglobin & $145.0 \mathrm{~g} / \mathrm{L}$ & $115-150 \mathrm{~g} / \mathrm{L}$ \\
Hematocrit & $46.80 \%$ & $35-45 \%$ \\
Platelet & $204 \times 10^{9} / \mathrm{L}$ & $125-350 \times 10^{9} / \mathrm{L}$ \\
MCHC & 310.0 & $316-354$ \\
Corpuscular volume & $46.8 \%$ & $40-50 \%$ \\
Mean RBC hemoglobin content & 28.10 & $27-34$ \\
\hline
\end{tabular}

$R B C$ red blood cell, $M C H C$ mean corpuscular hemoglobin concentration
The pain was centered in the position around the umbilicus. The flatus and defecation were normal. He showed no fever, hematemesis, hematochezia, diarrhea, melena, or weight loss upon admission. CT performed in a local hospital showed intussusception, intestinal effusion, and pneumatosis. There was no remission in the symptoms after conservative treatment. Besides, the abdominal symptoms showed gradual deterioration.

The findings for the laboratory examination were as follows: white cell count, $7.62 \times 10^{9} / \mathrm{L}$, neutrophils, $73.1 \%$; hemoglobin, $145.0 \mathrm{~g} / \mathrm{L}$; hematocrit, $46.80 \%$; platelet, 356 $\times 10^{9} / \mathrm{L}$ (Table 1$)$.

Abdominal CT scan revealed intussusception in the ascending colon (Fig. 1). The electrocardiogram and chest X-ray findings were normal.

For the treatment, the patient received surgery, in which the skin, subcutaneous tissues, anterior and posterior rectus sheath, and peritoneum were cut in turn. There was no abdominal distension or liquid overflow. The small intestine was slightly swollen and jasminecolored ascites $(500 \mathrm{ml})$ was seen in the pelvic cavity.

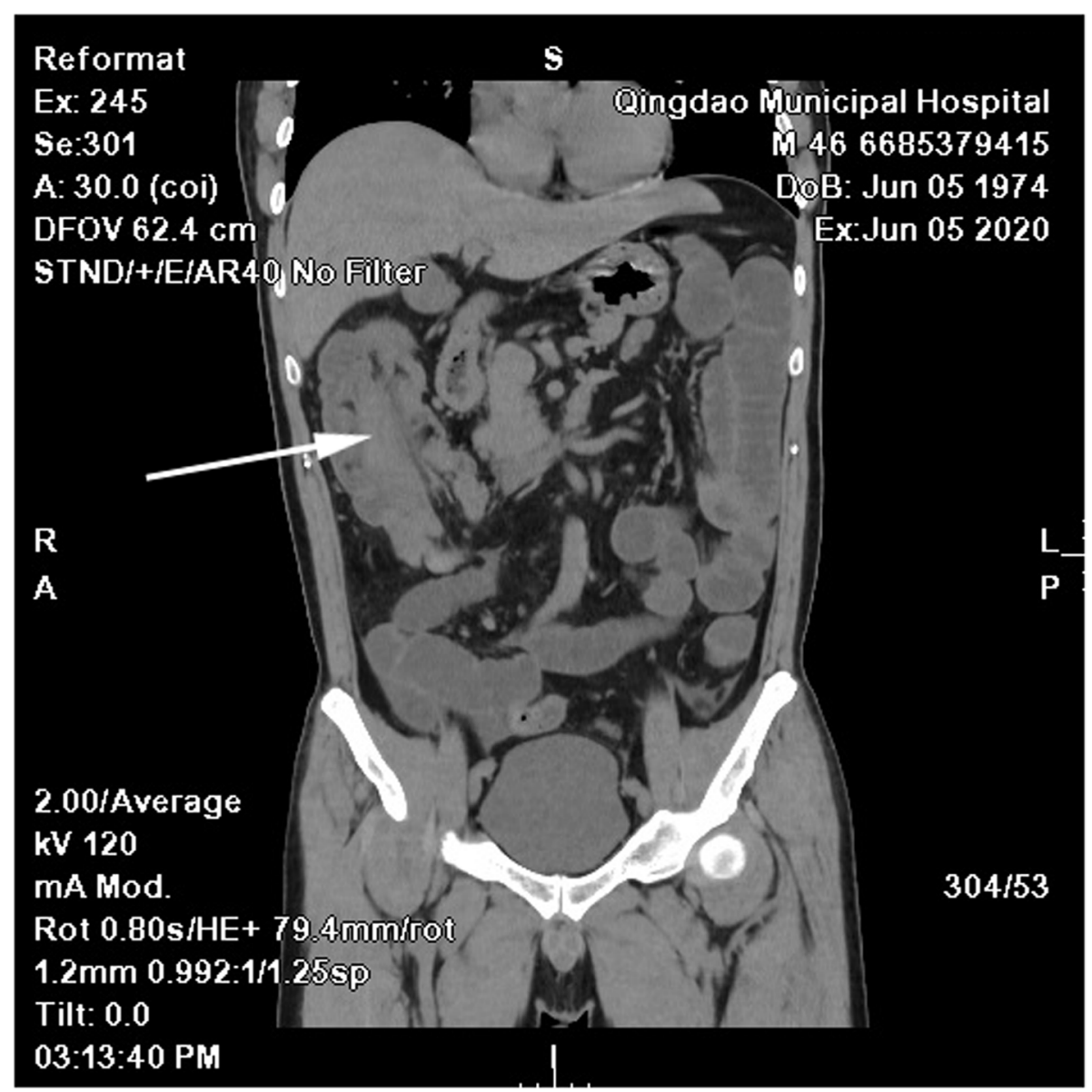

Fig. 1 Abdominal computed tomography view indicated ascending colon intussusception (grey arrow) 

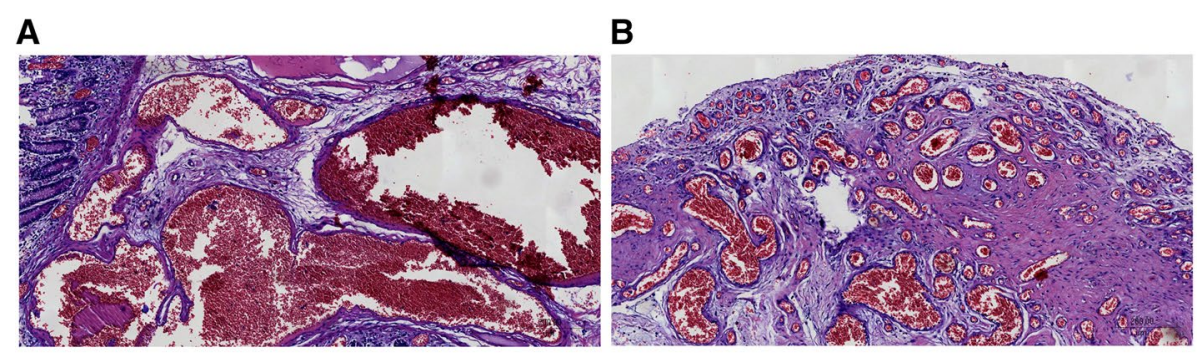

C

D
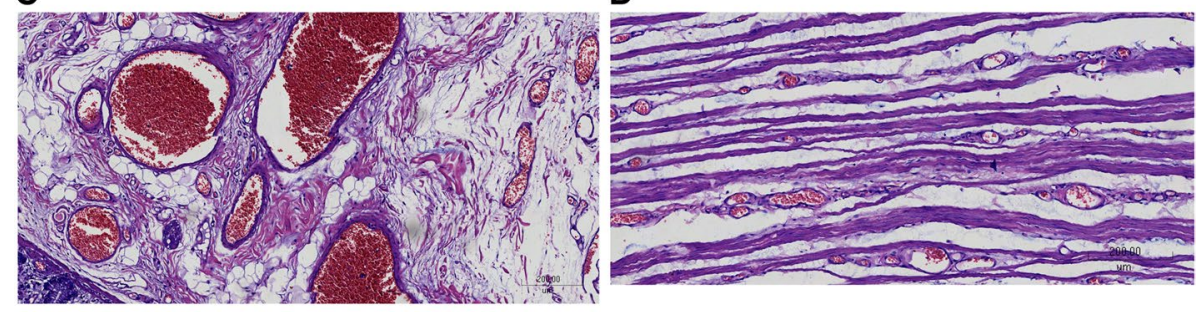

$\mathbf{E}$

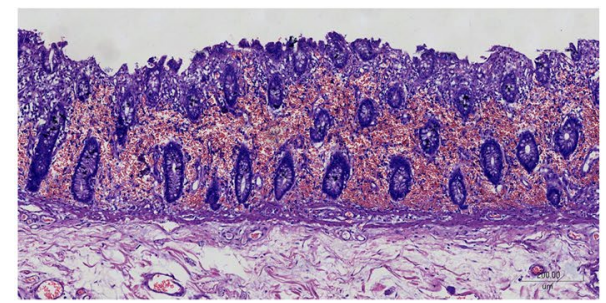

Fig. 2 The lesion was unencapsulated and composed of blood-filled spaces of variable size and shape. The lumens were filled with blood cells and lined by thin endothelial cells and separated by connective tissue stroma. The images were obtained after H\&E staining under a magnification of $100 \times$. A, $\mathbf{B}$ The lesion of distal ileum stated at submucosa or serosa. C, D The lesion of colon stated at submucosa or through the muscularis. $\mathbf{E}$ Some colon mucosa showed interstitial hemorrhage

The distal ileum, appendix, cecum, and greater omentum were found to be intussuscepted into the ascending colon. The length of the intussuscepted ileum was about $15 \mathrm{~cm}$. The root of appendix and cecal wall was hard, and there was purulent substance on the surface. The greater omentum showed adhesion to the cecal wall. There was slight enlargement in the lymph nodes of radix of mesentery. In addition, adhesion was seen in the lateral region of peritoneum.

For the histopathological characteristics, the intestinal wall of ileum, cecum, and ascending colon were thickened in a diffuse manner and the thickest part was about $0.8 \mathrm{~cm}$. The texture was hard and tough, with the serosal surface in a grayish color. Dilated lumen and blood clots were seen in the incisal surface. The mucosal surface of the ileum was erosive, and the colonic was smooth in a grayish-red color. The appendix showed a length of about $5 \mathrm{~cm}$ and a diameter of $1.5 \mathrm{~cm}$. The wall of the appendix was hard. Mucoid substance was observed in the appendix cavity near the root. Microscopically, there were blood-filled lumens or cavities in the ileum, cecum, colon submucosa and serosa, which were lined with a single layer of endothelial cells, and the cells were not heteromorphic (Fig. 2A-E). The interstitium was filled with loose fibrous connective tissue, and dilated vascular lumen was found in some muscular layers in smooth muscle bundles. There were proliferative capillaries and large thin-walled vascular lumen in ileum, cecum, mesentery of colon, and serous surface of appendix. Meanwhile, remarkable proliferation was noticed in the interstitial collagen fibers. No anastomosis was noticed in the interacted capillaries. The large vascular lumen was filled with red blood cells (RBCs), and the lumen was lined with monolayer endothelial cells of no atypia. The appendix cavity was completely filled in with mucus. In addition, the appendix lamina propria mucosa and muscularis mucosa were not available. Part of submucosa showed fibrosis. The wall of the appendix was lined with low-grade mucinous epithelium (Fig. 3A-E).

CT results indicated a high possibility of secondary intussusception. Histopathology confirmed mixed type of cavernous and capillary hemangioma, combined with LAMNs and intestinal obstruction. For the treatment, 


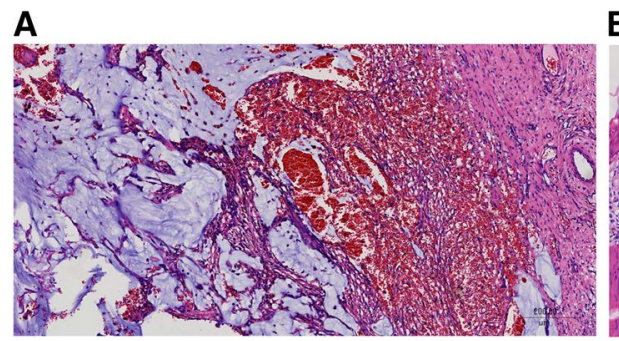

C

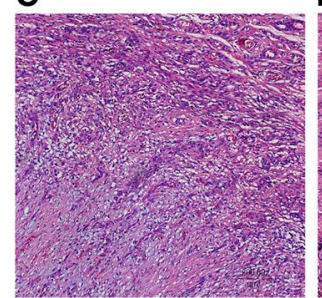

D

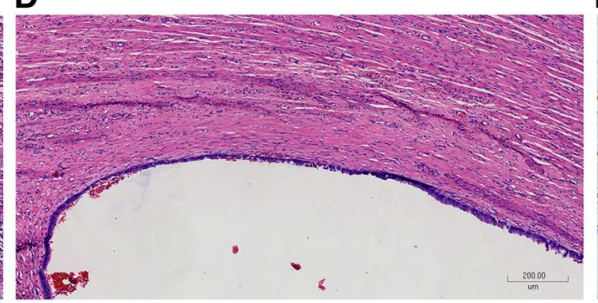

B

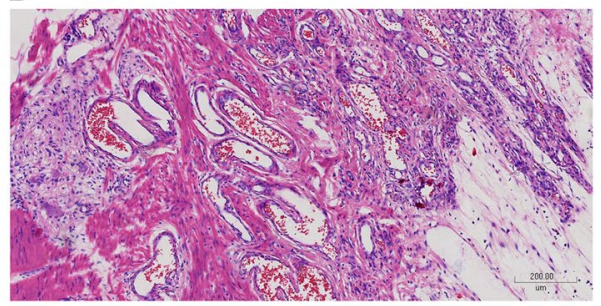

E

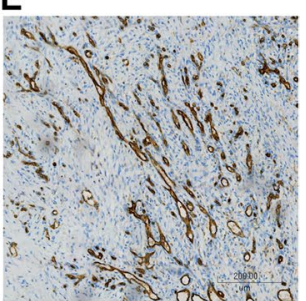

Fig. 3 Lesions of appendix with mixed capillary and cavernous hemangiomas and LAM. The images were obtained after H\&E staining under a magnification of 100x. A There was massive mucus, blood filled parenchymal vessels and hemorrhage in the appendiceal mucosa. B Spongy blood vessels of variable size and shape were seen, together with capillaries at the appendix muscularis and serosa. C Massive capillaries at the serosa. D The distended region of the appendix with thinned mucosa was reduced to a single columnar cell layer, with underlying fibrotic submucosa. The columnar cell was minimal atypia. E Immunohistochemical staining of CD31

the patient underwent laparotomy and right hemicolectomy. The postoperative recovery was good without any complications. The patient was followed up for 4 months, and no discomforts were reported by the patient until now.

\section{Discussion}

GI hemangiomas refer to a rare condition, with a prevalence of merely $0.05 \%$ [4] of all intestinal neoplasms and $2.8 \%$ of all intestinal neoplasms [5]. Grossly, GI hemangiomas could be presented as polypoid and intraluminal, or submucosal lesions with diffused or vague boundaries. Most of the lesions were in a color of purplish-red to blue with a soft and compressible texture unless containing a thrombus or phleboliths.

The disease was generally divided into three categories: (i) the capillary hemangioma, described as a small cluster of submucosal capillaries expanded intra-luminally, may develop into a stalk-like mass; (ii) a category represented by mixed capillary and cavernous hemangiomas; and (iii) the cavernous hemangioma, serving as the most common type. The histopathology of our case was mixed capillary and cavernous hemangiomas which involved small intestine, colorectal, and appendix.

The majority of cases with GI hemangiomas presented occult or acute gastrointestinal bleeding signs, followed by bowel obstruction, abdominal pain, perforation, or intussusception. In partial patients, there might be small polypoid lesions incidentally after endoscopy screening. In this case, the patient showed no bleeding or concealed hemorrhage. On this basis, the lesion was not detected in a long time.

Mucinous neoplasm of the appendix was an appendiceal neoplasm characterized by mucinous epithelial proliferation with extracellular mucin and pushing tumor margins. To date, little is known about the etiology of appendiceal mucinous neoplasms. In the 2019 WHO Classification of Tumors of the Digestive System $[3,6]$, the appendiceal mucinous neoplasm was excluded. According to the epithelial hyperplasia and morphology, the appendiceal mucinous neoplasm was defined as hyperplastic polyp, serrated lesions, LAMNs, HAMNs, and mucinous adenocarcinoma. The appendiceal mucinous cystadenoma was further defined as LAMNs. Diagnostic criteria for LAMNs was villous pseudostratified mucinous epithelium or monolayered mucinous cells with only mild atypia and with a broad pushing margin, fibrosis, hyalinization, and calcification of the appendiceal wall; various degrees of mucin dissection; and the absence of muscularis mucosa.

HAMNs show histological features similar to LAMNs, including subepithelial fibrosis, a broad pushing margin, broad-front pushing invasion, rupture, and peritoneal dissemination. The neoplastic epithelium has unequivocal high-grade features including enlarged, hyperchromatic, and pleomorphic nuclei, numerous atypical mitotic figures, single-cell necrosis, and sloughed necrotic epithelial cells in the lumen of the appendix. In cases of an infiltrative pattern, there would be stromal desmoplasia and mucin pools with atypical 
cells, as well as content of extracellular mucin $>50 \%$ in the lesions. Such condition was defined as mucinous adenocarcinoma.

The clinical symptoms of patients with peritoneal dissemination included progressive abdominal distention, new onset of an umbilical hernia, or a palpable mass after abdominal or pelvic examinations. There might be a soft tissue mass in the appendix that was manifested as hydrops after CT or ultrasonography. To our best knowledge, curvilinear calcification of the wall was the specific lesions, but they were presented in only half of the cases. Our case showed features of hemangiomas of small intestine, cecum and appendix combined with LAMNs.

The prognosis of LAMN is highly depending on the tumor stage [3]. Those with tumors limited to the appendix showed a good prognosis, while those with peritoneal dissemination were reported to show a variable prognosis. The prognosis in disseminated tumors depended on the grade of the peritoneal mucinous epithelium, disease severity, and the ability to achieve complete cytoreduction of macroscopically visible tumor within the abdomen. Hyperthermic intraperitoneal chemotherapy and complete cytoreduction may cause clinical benefits to the patients' survival. As rare cases are diagnosed with HAMNs, there are limited data regarding their natural history when they are confined to the appendix. Currently, the management of HAMNs was limited to the appendix, and the efficiency of additional surgery is still uncertain. HAMNs patients disseminated to the peritoneal cavity are likely to behave like other mucinous tumors spread to the peritoneum. In our study, the patient was diagnosed with LAMNs with no tumor rupture, and the prognosis was satisfactory in the 4-month follow-up after surgery.

Intussusception is primarily a disease in childhood and is relatively rare in adults. Unlike childhood intussusception, adult intussusception shows identifiable lesions such as malignant or benign neoplasms. However, intussusception caused by hemangioma is a very rare entity. In our literature search, we searched the articles on intestinal hemangioma and intussusceptions published between January 2000 and February 2021 using the following key words: "gastrointestinal hemangioma" and "intussusception". Finally, 10 articles [6-15] in English with intestinal hemangioma and intussusception were identified. Among these articles, 4 cases [7-10] were about blue rubber bleb nevus syndrome, which was a hereditary cutaneous syndrome characterized by cavernous hemangiomas of skin and GI tract that were thought to represent hamartomas. One case was diagnosed with PHACES syndrome, a newly defined rare congenital disease of hemangioma combined with other organ deformity, which was associated with intestinal hemangioma causing recurrent intussusceptions [6]. Specifically, one case [11] was child and two [12,13] were teenagers. Only two cases $[14,15]$ of adult hemangioma were described (Table 2).

Clinically, GI hemangiomas are symptomatic in $90 \%$ of cases, unlike other benign tumors of the GI tract that were symptom-free. The most frequent sign was chronic GI bleeding, which caused anemia of an unknown origin and massive bleeding under a rare condition. Occasionally, these tumors may cause intestinal obstructions, intussusception, intramural hematoma, perforation, and platelet sequestration. In a previous study, Fu et al. [16] reported that only a small part of patients $(4 \%)$ showed shock and intestinal obstructions caused by gastrointestinal hemangioma. In our case, the routine blood examination findings including RBCs, hemoglobin, hematocrit, mean corpuscular volume, and average RBC hemoglobin content, were all in normal ranges. The mean corpuscular hemoglobin concentration was slightly lower than normal range. The fecal occult blood test findings were all negative. There were no bleeding-related symptoms and signs. Among the 10 patients with intussusception obtained after literature search, abdominal pain was the main clinical symptom in $8(80.0 \%)$ patients, followed by nausea or 7 vomiting $(70.0 \%)$, and 5 intestinal bleeding (50.0\%). Based on the histological examinations, 5 cases were confirmed with cavernous hemangioma, 2 with capillary hemangioma, and 2 case with mixed capillary and cavernous hemangiomas, and 1 case with diffuse infantile hemangioma.

Histologically, our case was diagnosed with mixed capillary and cavernous hemangiomas. Indeed, rare adult cases showed intussusception caused by multiple hemangiomas. To our best knowledge, rare cases showed hemangiomas of small intestine, accompanied by large intestine and appendix.

Appendiceal intussusception is a rare condition presenting as acute appendicitis. It is still a challenge in the clinical diagnosis. In a previous study by Collins et al., the authors conducted a 40-year prospective study involving 71,000 cases underwent appendectomy, which indicated an incidence of $0.01 \%$ for the appendiceal intussusception [17]. As previously described, the appendiceal intussusception is usually induced by irregular appendiceal peristalsis developed by local irritation, which is more likely to occur in cases with mobile mesoappendix, enlarged appendicular lumen, and thin appendicular wall [18].

In our case, there were a large amount of mucus in the lumen of appendix and abundant dilated capillaries in the mucinous interstitium and the wall of the appendix. Besides, neoplastic hyperplasia of capillaries was seen on the serous surface. The patient was finally diagnosed with mixed hemangioma of the appendix combined 


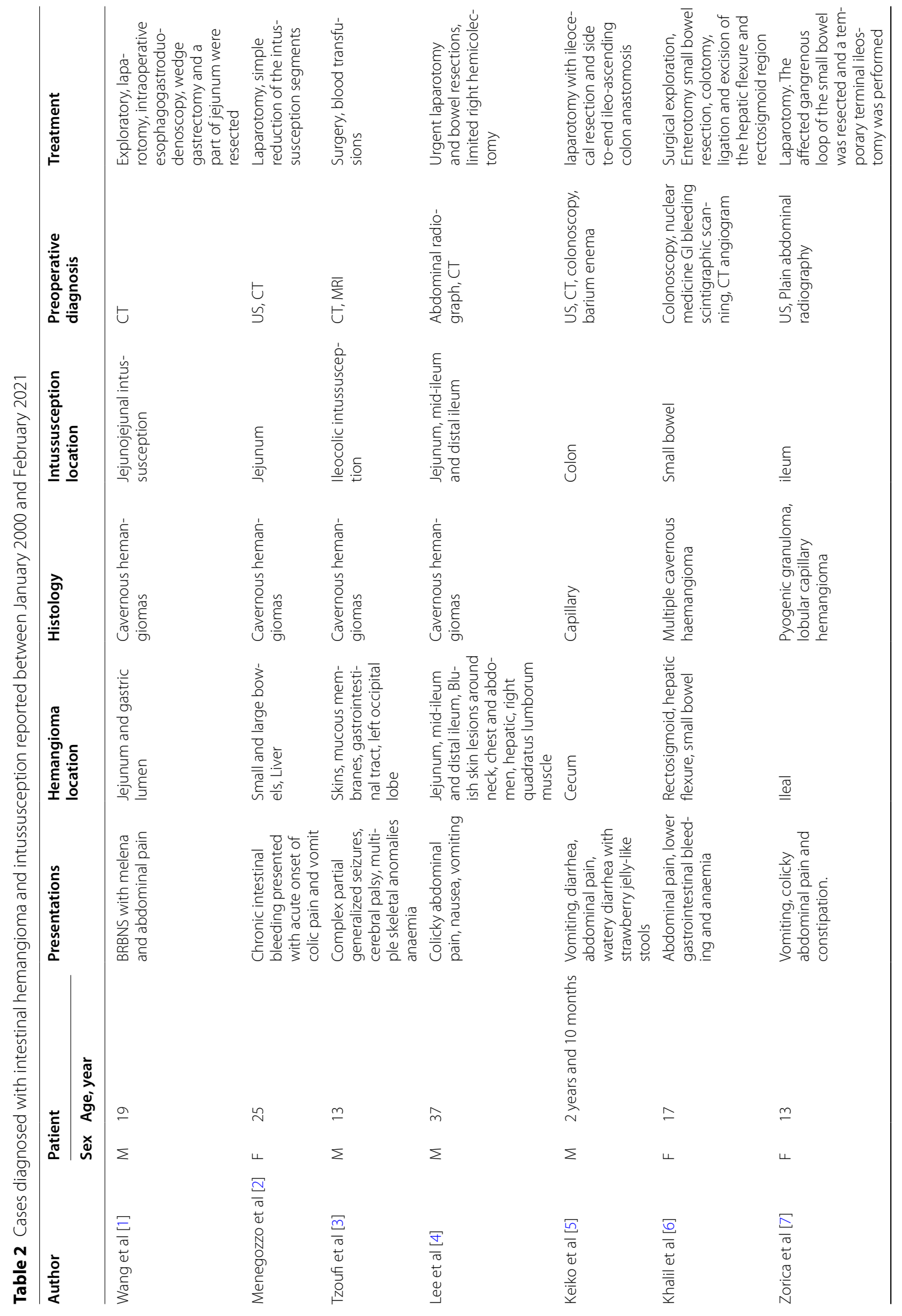




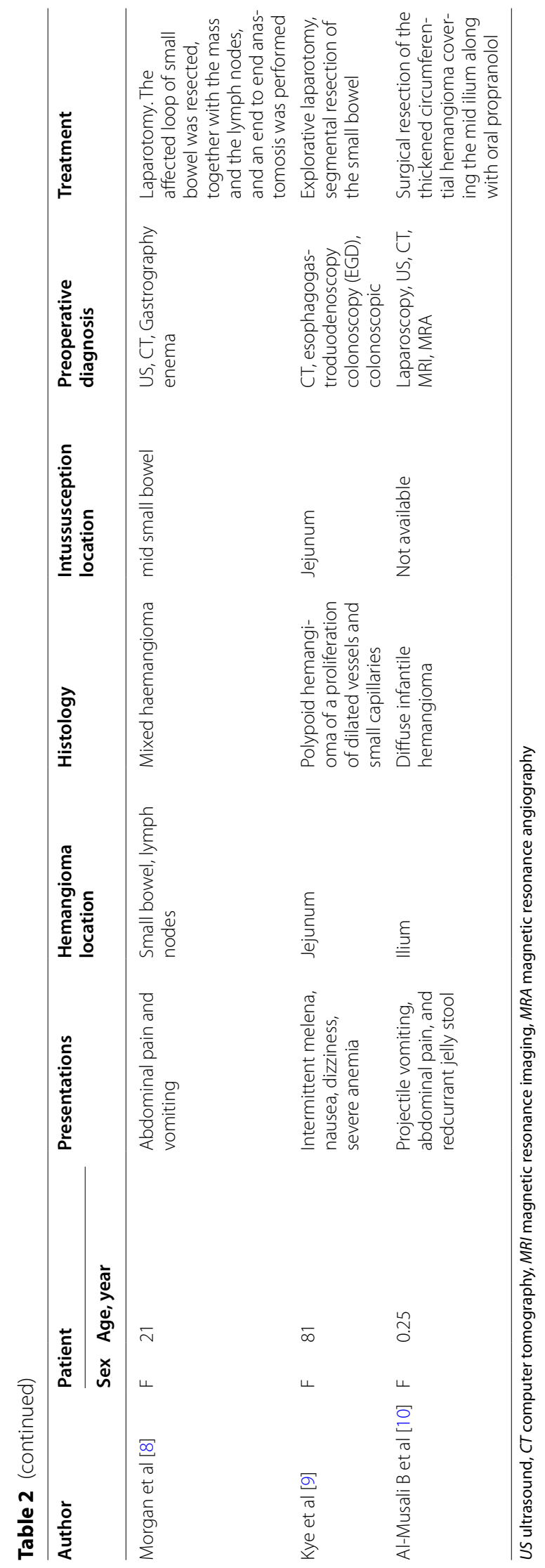




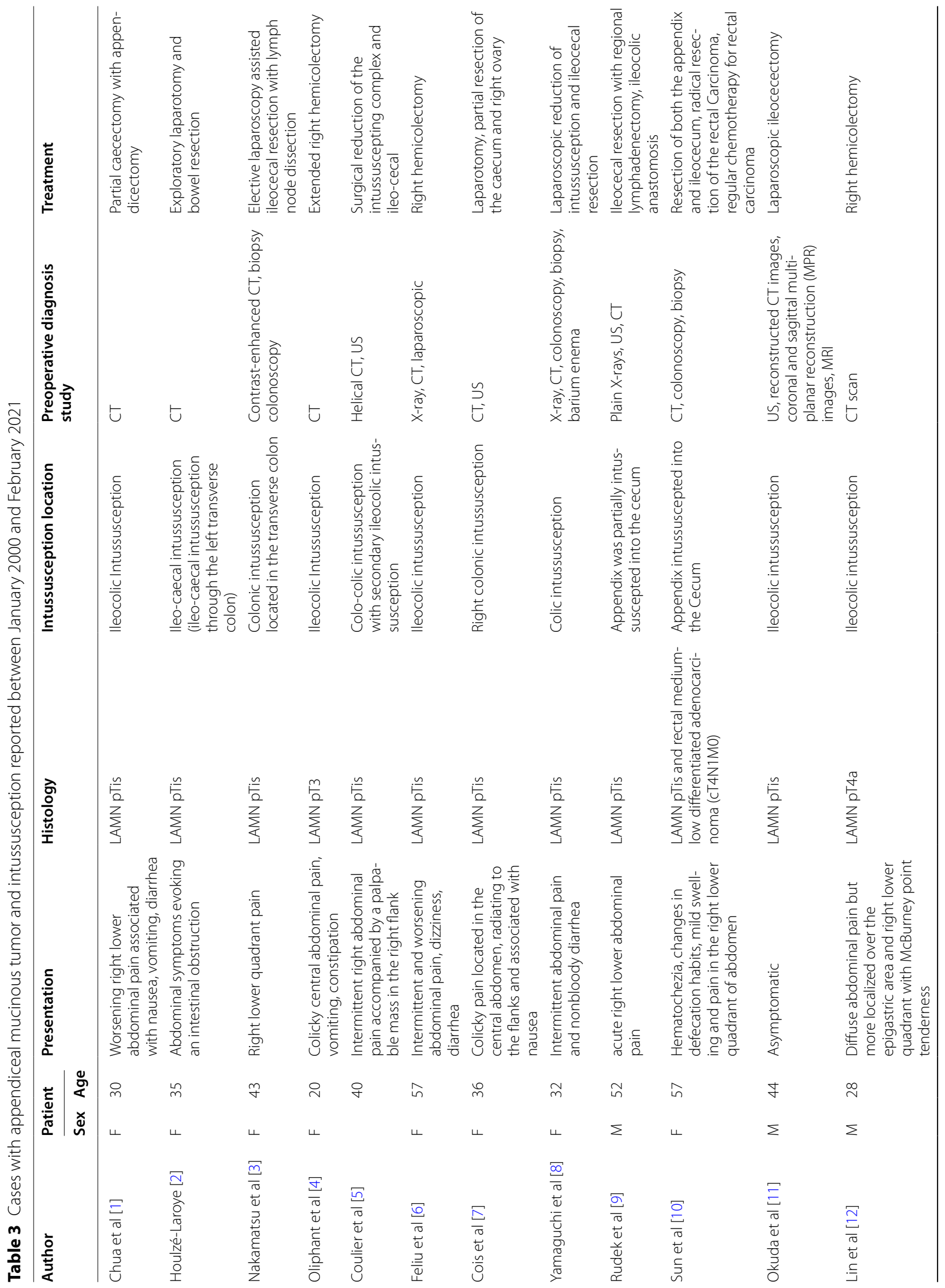




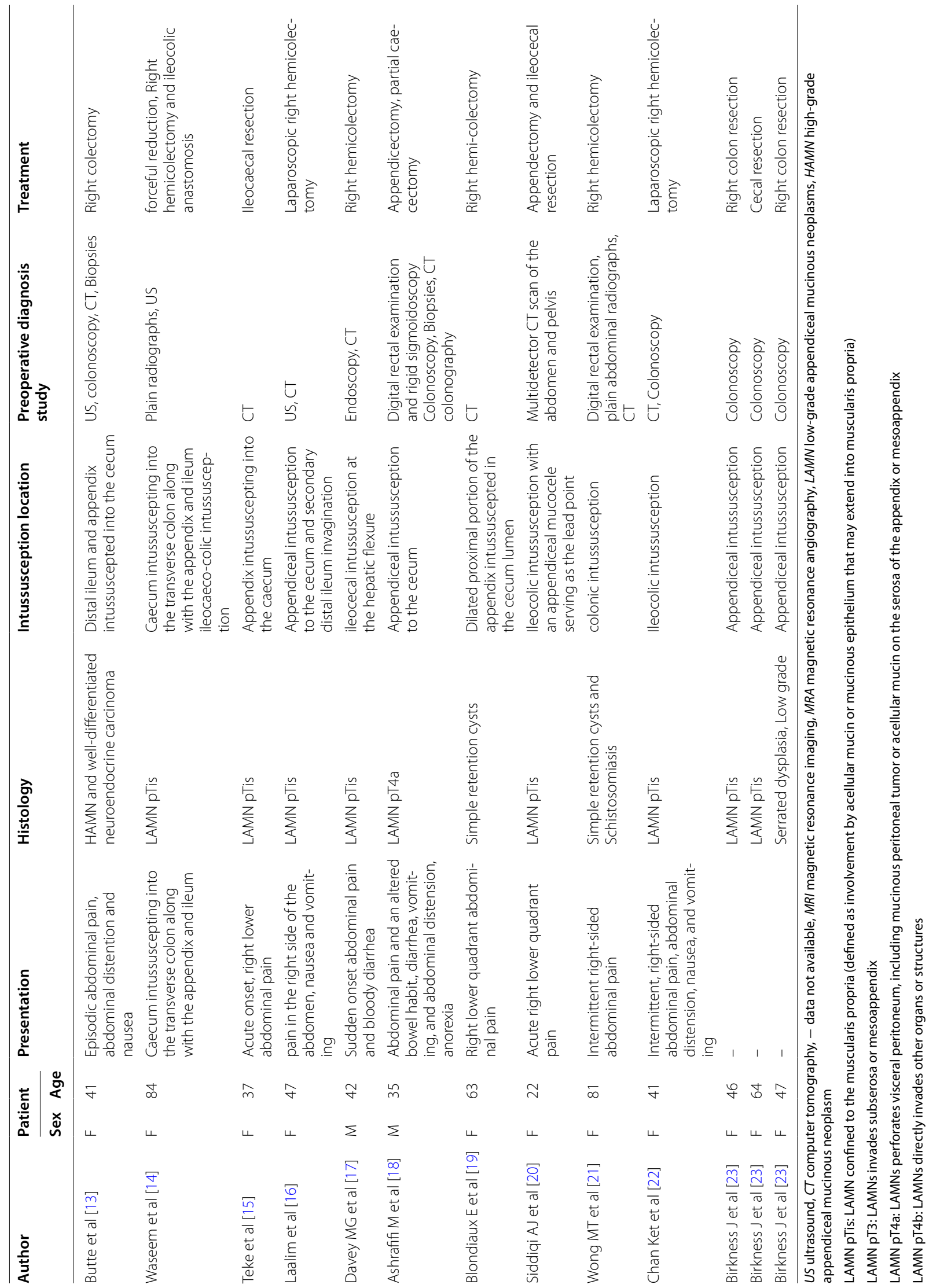


with low-grade mucinous tumor. Based on the literature search using the term "appendiceal mucinous tumor" and "intussusception" from the articles in the PubMed database between January 2000 and February 2021, 29 articles [19-47] were obtained, among which 20 [19-21, 23, 24, 26-40] were eligible after excluding 9 articles including 2 [22, 47] in Japanese language and 1[25] in Dutch, $2[41,42]$ involved the cases with no appendiceal mucinous tumor, $2[44,46]$ with appendiceal mucinous tumor with no intussusception, 1 [45] with sigmoidorectal intussusception caused by a mucinous adenocarcinoma of the sigmoid colon, as well as 1 study [43] focused on the histological and imaging features. Among the remaining 20 articles, one article [26] mentioned 3 related cases in the literature review including 1 with LAMNs induced intussusception, 1 with intussusception caused by appendiceal mucocele [48], and 1 with intussusception caused by appendiceal mucocele combined with schistosomiasis [49]. Mucocele was non-neoplastic mucinous lesion characterized by markedly thinned or denuded mucosa combined with luminal dilatation, without atypia and hyperplasia. In addition, one article concerning the clinicopathologic features of 21 cases of inverted appendix reporting 3 cases met the demands of the literature search [40]. Finally, 25 cases were included (Table 3). Then these cases were re-evaluated according to the classification standard in 2019 [1, 3]; among these cases, $18(72.0 \%)$ were confirmed with LAMNs pTis. Specifically, one case was diagnosed LAMNs pTis with rectal medium-low differentiated adenocarcinoma [30]. One case was diagnosed LAMNs pTis associated with ovarian cyst of the follicular-luteinic type [27]. One case (4.0\%) was diagnosed with simple retention cysts [49], one $(4.0 \%)$ with simple retention cysts and Schistosomiasis [50], one $(4.0 \%)$ with serrated dysplasia of low grade [40], one (4.0\%) with LAMNs pT3 [23], two (8.0\%) with LAMNs pT4a [32, 38], as well as one $(4.0 \%)$ with HAMNs of the appendix and well-differentiated neuroendocrine carcinoma [33]. For the classification of intussusception, 8 cases $(36.2 \%)$ were appendix intussuscepting into the caecum, and 15 cases $(60.0 \%)$ were colonic intussusception. In addition, one case showed Colo-colic intussusception with secondary ileocolic intussusception. One case showed distal ileum and appendix intussuscepted into the cecum.

Appendiceal mucinous tumor and intestinal hemangioma were considered to lead to intussusception based on literature review. Intussusception caused by appendiceal mucinous tumor is more common than that caused by adult hemangioma. In our case, a large amount of mucus was observed in the appendix cavity, and there was more mucus in the residual mucosa interstitium of the appendix. Meanwhile, capillary proliferation was seen in the mucous background. A large number of new neovascularization was found in the submucosa, muscular layer and serosa surface of ileum, as well as cecum appendix and colon. We speculated that appendiceal mucinous tumor may lead to stiffness of intestinal wall, and disorder of peristalsis rhythm. On this basis, it may affect the blood circulation of local tissues, and then the congestion and telangiectasia would result in aggravation in the formation of new capillaries. In cases of hemangioma of colon and ileocecal region, hemangioma would greatly increase the load of intestinal peristalsis, which is likely to induce dysfunction of intestinal movement. Therefore, it may induce the accumulation of appendix mucus, which led to a possibility of occurrence and/or progression of low-grade mucinous tumors of the appendix. It has been well acknowledged that both appendiceal mucinous tumor and intestinal diffuse hemangioma are chronic processes. No matter which showed onset first or collision, the disorder of intestinal blood supplies and mucinous tumor all can lead to the disorder of intestinal movement rhythm. Mucinous tumor and hemangioma contributed to their mutual progression, which eventually resulted in intussusception. Pathological analysis indicated no necrosis in the colon wall. Besides, only erosion of the epithelium and the hemorrhage of the lamina propria were seen on the mucosal surface, which further confirmed that the occurrence of intussusception in our case was a chronic process. In the 4-month follow-up, the symptoms of gastrointestinal disorders showed attenuation with no significant postoperative complication.

\section{Conclusion}

Multiple hemangiomas of small and large intestine are rare in adults. Rare studies reported the intestine hemangiomas coincided with appendix low-grade mucinous tumor. In clinical settings, the manifestations were not specific, which was a challenge in the preoperative diagnosis. For cases with intussusception that was not observed in time, it may lead to intestinal necrosis and diffuse peritonitis. In this study, we described a rare case with intussusception caused by either intestinal hemangiomas or appendiceal mucinous neoplasms. We described a possibility of intussusception. In addition, contrast-enhanced CT scan clearly showed hemangioma and mucous lesions. In this study, the patient underwent plain CT scan, which confirmed the presence of intussusception. On this basis, exploratory laparotomy and surgery were conducted. In the presence of confirmed diagnosis, the surgery should be given.

\section{Abbreviations}

Gl: Gastrointestinal; LAMNS: Low-grade appendiceal mucinous neoplasms; HAMNS: High-grade appendiceal mucinous neoplasms. 


\section{Acknowledgements \\ Not applicable.}

\section{Authors' contributions}

YYH wrote the manuscript; JC revised the manuscript; JDM did the data analysis and collection. All authors have read and approved the manuscript.

\section{Funding}

None.

\section{Availability of data and materials}

The datasets used and analyzed during the current study are available from the corresponding author on reasonable request.

\section{Declarations}

\section{Ethics approval and consent to participate}

The study protocols were approved by the Ethical Committee of Qingdao Municipal Hospital. The consent was obtained from the patient.

\section{Consent for publication}

Written informed consent was obtained from the participants for publication of this article and any accompanying tables/images. A copy of the written consent is available for review by the Editor of this journal.

\section{Competing interests}

The authors declare no competing interests.

Received: 10 December 2021 Accepted: 28 January 2022

Published online: 23 February 2022

\section{References}

1. Koç C, Akbulut S, Akatlı AN, Türkmen Şamdancı E, Tuncer A, Yılmaz S. Nomenclature of appendiceal mucinous lesions according to the 2019 WHO Classification of Tumors of the Digestive System. Turk J Gastroenterol. 2020;31(9):649-57.

2. Akbulut S, Sahin TT. Comment on management and prognosis of lowgrade appendiceal mucinous neoplasms: a clinicopathologic analysis of 50 cases. Eur J Surg Oncol. 2020;46(12):2338.

3. WHO Classification of Tumours Editorial Board. Digestive System Tumours. In: WHO Classification of Tumours, 5th Edition. Lyon: International Agency for Research on Cancer; 2019. p. 144-46.

4. Boyle L, Lack EE. Solitary cavernous hemangioma of small intestine. Case report and literature review. Arch Pathol Lab Med. 1993;117(9):939-41.

5. Bamanikar AA, Diwan AG, Benoj D. Gastric hemangioma: an unusual cause of upper gastrointestinal bleed. Indian J Gastroenterol. 2004;23(3):113-4

6. Al-Musalhi B, Al-Balushi Z. PHACES syndrome with intestinal hemangioma causing recurrent intussusceptions: a case report and literature review of associated intestinal hemangioma. Oman Med J. 2020;35(6):e204.

7. Wang Y, Zhao X, You X. Blue rubber bleb nevus syndrome coexisted with intestinal intussusception: a case report. Pan Afr Med J. 2014:17:212.

8. Menegozzo CAM, Novo F, Mori ND, Bernini CO, Utiyama EM. Postoperative disseminated intravascular coagulation in a pregnant patient with Blue Rubber Bleb Nevus Syndrome presenting with acute intestinal obstruction: case report and literature review. Int J Surg Case Rep. 2017:39:235-8

9. Tzoufi MS, Sixlimiri P, Nakou I, Argyropoulou MI, Stefanidis CJ, Siamopoulou-Mavridou A. Blue rubber bleb nevus syndrome with simultaneous neurological and skeletal involvement. Eur J Pediatr. 2008;167(8):897-901.

10. Lee C, Debnath D, Whitburn T, Farrugia M, Gonzalez F. Synchronous multiple small bowel intussusceptions in an adult with blue rubber bleb naevus syndrome: Report of a case and review of literature. World J Emerg Surg. 2008;3:3.

11. Utsumi K, Ogasawara N, Sasaki M, et al. Intussusception in a child caused by capillary hemangioma of the colon. Clin J Gastroenterol. 2010:3(2):83-7.

12. ElGendy K, Salem A. Multiple intestinal haemangiomas presenting as intussusception and bleeding. BMJ Case Rep. 2014;2014:bcr2014206365.
13. Stojsic Z, Brasanac D, Kokai G, et al. Intestinal intussusception due to a pyogenic granuloma. Turk J Pediatr. 2008;50(6):600-3.

14. Morgan DR, Mylankal K, el Barghouti N, Dixon MF. Small bowel haemangioma with local lymph node involvement presenting as intussusception. J Clin Pathol. 2000;53(7):552-3.

15. Kye BH, Kim SH, Lee Il, et al. Hemorrhage from a jejunal polypoid hemangioma: single incisional laparoscopic approach. J Korean Surg Soc. 2011;80(5):362-6.

16. Fu JX, Zou YN, Han ZH, Yu H, Wang XJ. Small bowel racemose hemangioma complicated with obstruction and chronic anemia: a case report and review of literature. World J Gastroenterol. 2020;26(14):1674-82.

17. Langsam LB, Raj PK, Galang CF. Intussusception of the appendix. Dis Colon Rectum. 1984;27(6):387-92.

18. Navarra G, Asopa V, Basaglia E, Jones M, Jiao LR, Habib NA. Mucous cystadenoma of the appendix: is it safe to remove it by a laparoscopic approach? Surg Endosc. 2003;17(5):833-4.

19. Chua TC, Gill P, Gill AJ, Samra JS. Ileocecal intussusception caused by an appendiceal neoplasm. J Gastrointest Surg. 2016;20(4):867-8.

20. Houlzé-Laroye C, Eveno C. Low-grade appendiceal mucinous neoplasms with bowel obstruction. Pleura Peritoneum. 2019;4(3):20190020.

21. Nakamatsu D, Nishida T, Yamamoto M, Matsubara T, Hayashi S. Colon intussusceptions caused by a low-grade appendiceal mucinous neoplasm. Indian J Gastroenterol. 2018;37(5):475-6.

22. Mitsuoka A, Kuwabara $H$, Watanabe $\mathrm{S}$, et al. A case of intussusception caused by low-grade appendiceal mucinous neoplasm with high serum levels of carcinoembryonic antigen resected by laparoscopy-assisted colectomy. Gan To Kagaku Ryoho. 2013;40(12):1944-6.

23. Oliphant R, Balsitis M, Doherty G, Felsenstein I. Ileocolic intussusception secondary to a type II low-grade appendiceal mucinous neoplasm. Colorectal Dis. 2013;15(4):e200-1.

24. Coulier B, Pestieau S, Hamels J, Lefebvre Y. US and CT diagnosis of complete cecocolic intussusception caused by an appendiceal mucocele. Eur Radiol. 2002;12(2):324-8.

25. Oosterwijk AJM, van den Berg JW, van Rossem CC. A man with abdominal pain, diarrhoea and rectal bleeding. Ned Tijdschr Geneeskd. 2018;162:D2050.

26. Feliu F, Rueda JC, Escuder J, Gris F, Jiménez A, Vicente V. Adult intussusception of appendicular mucinous cystoadenoma. Int Surg. 2013:98(4):392-8

27. Cois A, Pisanu A, Pilloni L, Uccheddu A. Intussusception of the appendix by mucinous cystadenoma. Report of a case with an unusual clinical presentation. Chir Ital. 2006;58(1):101-4.

28. Yamaguchi S, Fujii S, Ike H, Shimada H. Laparoscopic reduction of appendicocecal intussusception due to mucinous cystadenoma in an adult. Jsls. 2004;8(3):279-82.

29. Rudek B, von Herbay A, Schmidt J. Intussusception of the appendix secondary to mucinous cystadenoma. Dig Surg. 2001;18(5):422-6.

30. Sun Z, Wang H, Yu X, Zhao Z, Wang Q. Appendiceal mucinous cystadenoma intussuscepted into the cecum on a patient with rectal carcinoma: a case report. J Gastrointest Cancer. 2014;45(Suppl 1):112-4.

31. Okuda I, Matsuda M, Noguchi H, Kokubo T. Massive mucinous cystadenoma of the appendix with intussusception in an adult: usefulness of reconstructed computed tomography images. Radiat Med. 2008;26(2):88-91.

32. Wei-Ming L, Chih-Hui L, Kuo LM, Yang BY. Intussusception secondary to a giant appendiceal mucocele: preoperative diagnosis by multi-slice computed tomography. Abdom Imaging. 2010;35(4):428-30.

33. Butte JM, Torres J, Henríquez IM, Pinedo G. Appendicular mucosal intussusception into the cecum secondary to an intramural mucinous cystoadenoma of the appendix. J Am Coll Surg. 2007;204(3):510.

34. Waseem T, Sabir NU, Hussain S, Amir E, Arif S. Rare association: ileocaecocolic intussusception secondary to mucinous cystadenoma of the appendix in an adult. ANZ J Surg. 2007;77(11):1021-2.

35. Teke Z, Eray IC, Aydin E, Ortlek AB. Appendiceal intussusception caused by mucinous cystadenoma presenting as acute appendicitis. Ann R Coll Surg Engl. 2020;102(4):e1-4.

36. Laalim SA, Toughai I, Benjelloun el B, Majdoub KH, Mazaz K. Appendiceal intussusception to the cecum caused by mucocele of the appendix: laparoscopic approach. Int J Surg Case Rep. 2012;3(9):445-7.

37. Davey MG, Conlon ET, Forde G, Byrnes VM, Carroll PA. Adult intussusception secondary to an appendiceal tumour in a patient with ulcerative colitis: a case report. Surg Case Rep. 2020;6(1):234. 
38. Ashrafi M, Joshi V, Zammit M, Telford K. Intussusception of the appendix secondary to mucinous cystadenoma: a rare cause of abdominal pain. Int J Surg Case Rep. 2011;2(2):26-7.

39. Chan K, Tan KK. Cecal pole mass causing intussusception. Gastroenterology. 2014;147(5):979-80.

40. Birkness J, Lam-Himlin D, Byrnes K, Wood L, Voltaggio L. The inverted appendix - a potentially problematic diagnosis: clinicopathologic analysis of 21 cases. Histopathology. 2019;74(6):853-60.

41. Park BS, Shin DH, Kim DI, Son GM, Kim HS. Appendiceal intussusception requiring an ileocecectomy: a case report and comment on the optimal surgery. BMC Surg. 2018;18(1):48.

42. Vyas M, Wong S, Zhang X. Intestinal metaplasia of appendiceal endometriosis is not uncommon and may mimic appendiceal mucinous neoplasm. Pathol Res Pract. 2017;213(1):39-44.

43. Pickhardt PJ, Levy AD, Rohrmann CA Jr, Kende Al. Primary neoplasms of the appendix: radiologic spectrum of disease with pathologic correlation. Radiographics. 2003;23(3):645-62.

44. Kim-Fuchs C, Kuruvilla YC, Angst E, Weimann R, Gloor B, Candinas D. Appendiceal mucocele in an elderly patient: how much surgery? Case Rep Gastroenterol. 2011:5(3):516-22.

45. Dell'abate P, Del Rio P, Sommaruga L, Arcuri MF, Sianesi M. Laparoscopic treatment of sigmoid colon intussusception by large malignant tumor. Case report. G Chir. 2009;30(8-9):374-6.

46. Sato H, Fujisaki M, Takahashi T, Maruta M, Maeda K, Kuroda M. Mucinous cystadenocarcinoma in the appendix in a patient with nonrotation: report of a case. Surg Today. 2001;31(11):1012-5.

47. Kishikawa H, Nishida J, Nakano M, et al. A case of adult onset intussusception for mucinous cystoadenoma of appendix presented as acute abdomen. Nihon Shokakibyo Gakkai Zasshi. 2003;100(3):328-32.

48. Siddiqi AJ, Arafat O, Nikolaidis P, Yaghmai V. MDCT diagnosis of ileocolic intussusception secondary to an appendiceal mucocele: value of multiplanar reformation. Emerg Radiol. 2007;13(5):273-5.

49. Blondiaux E, Savoye-Collet C, Foulatier O, Lemoine F, Dacher JN. Appendiceal intussusception caused by a mucocele of the appendix: imaging findings. Dig Liver Dis. 2007;39(12):1087.

50. Wong MT, Goh L, Chia KH. Intestinal schistosomiasis manifesting as colonic intussusception arising from a mucocele of the appendix: report of a case. Surg Today. 2008;38(7):664-7.

\section{Publisher's Note}

Springer Nature remains neutral with regard to jurisdictional claims in published maps and institutional affiliations.

Ready to submit your research? Choose BMC and benefit from:

- fast, convenient online submission

- thorough peer review by experienced researchers in your field

- rapid publication on acceptance

- support for research data, including large and complex data types

- gold Open Access which fosters wider collaboration and increased citations

- maximum visibility for your research: over $100 \mathrm{M}$ website views per year

At BMC, research is always in progress.

Learn more biomedcentral.com/submissions 